\title{
Correspondence
}

\section{Recalcitrant pemphigus vulgaris: aseptic meningitis associated with intravenous immunoglobulin therapy and successful treatment with rituximab \\ Dear Sir,}

We report the case of a 26-year-old woman with a 5 -year history of a severe and recalcitrant pemphigus vulgaris (PV) (Fig. I). During this period, the patient was treated with prednisolone, first combined with azathioprine and later with mycophenolate mofetil, but without complete response and always worsening when
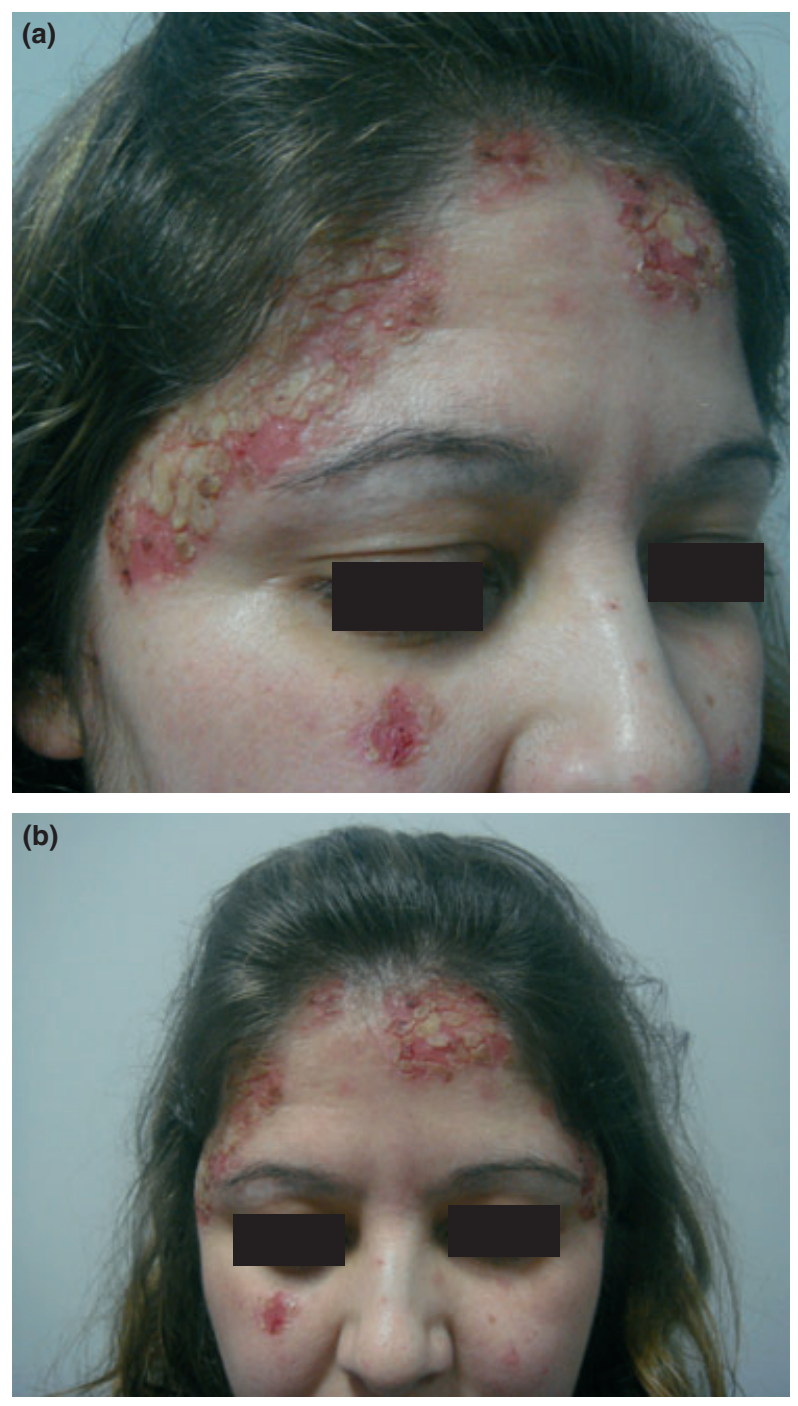

Figure 1 (a) and (b) Pemphigus vulgaris: lesions on the face despite combination therapy prednisolone tapering was attempted. In this setting, she was treated with intravenous immunoglobulin (IVIG) $(2 \mathrm{~g} / \mathrm{kg}$ over three days) in combination with prednisolone $(40 \mathrm{mg} / \mathrm{d})$. On the third day of IVIG, she presented with severe headache, nuchal rigidity, photophobia, and nausea. Neurological examination was otherwise normal as was the brain computed tomography scan. Lumbar puncture was performed, and the cerebrospinal fluid predominantly showed a raised white cell lymphocyte count $(80 / \mu \mathrm{l})$ with normal glucose and protein contents. Cerebrospinal fluid culture and polymerase chain reaction for common viruses were both negative. These findings supported the diagnosis of aseptic meningitis secondary to immunoglobulin infusion. She recovered over the next 48 hours without any medication, and she was discharged after four days.

The PV continued to worsen with numerous active lesions mostly on the scalp, face, back, and oral mucosa. Cyclosporine in association with prednisolone and mycophenolate mofetil had no benefit. Finally, rituximab $375 \mathrm{mg} / \mathrm{m}^{2}$ IV weekly, over four consecutive weeks, was tried. After the second infusion, lesions began to heal, with complete re-epithelization two months after treatment. No relevant side effects were reported. After one year, the patient is doing well, without lesions (Fig. 2).

It should be noted in this case the occurrence of aseptic meningitis as a serious side effect of treatment with IVIG and the good response to rituximab. In fact, IVIG therapy is widely used in autoimmune diseases and usually recognized as a safe biologic agent. ${ }^{\mathrm{I}}$ Aseptic meningitis is one of the uncommon severe adverse reactions of IVIG therapy. $^{2}$ The incidence ranges from II $\%$ to $17 \% .^{3}$ The mechanism for IVIG-induced aseptic meningitis is not well understood. Studies showed that severe adverse events might be minimized by enforcing a slow administration rate and adequate hydration. ${ }^{2}$

Rituximab results in the depletion of normal as well as malignant B cells, leading to investigation of its use in autoimmune disorders, particularly in the treatment of systemic lupus erythematosus ${ }^{4}$ and rheumatoid arthritis. ${ }^{5}$ Although there have been no randomized controlled trials of rituximab in dermatologic disease, case reports describe its use in PV, paraneoplastic pemphigus, epidermolysis bullosa acquisita, cutaneous B-cell lymphoma, dermatomyositis, graft-versus-host disease, Wegener's granulomatosis, microscopic polyangiitis, cryoglobulinemic vasculitis, and Churg-Strauss syndrome. ${ }^{6}$ 

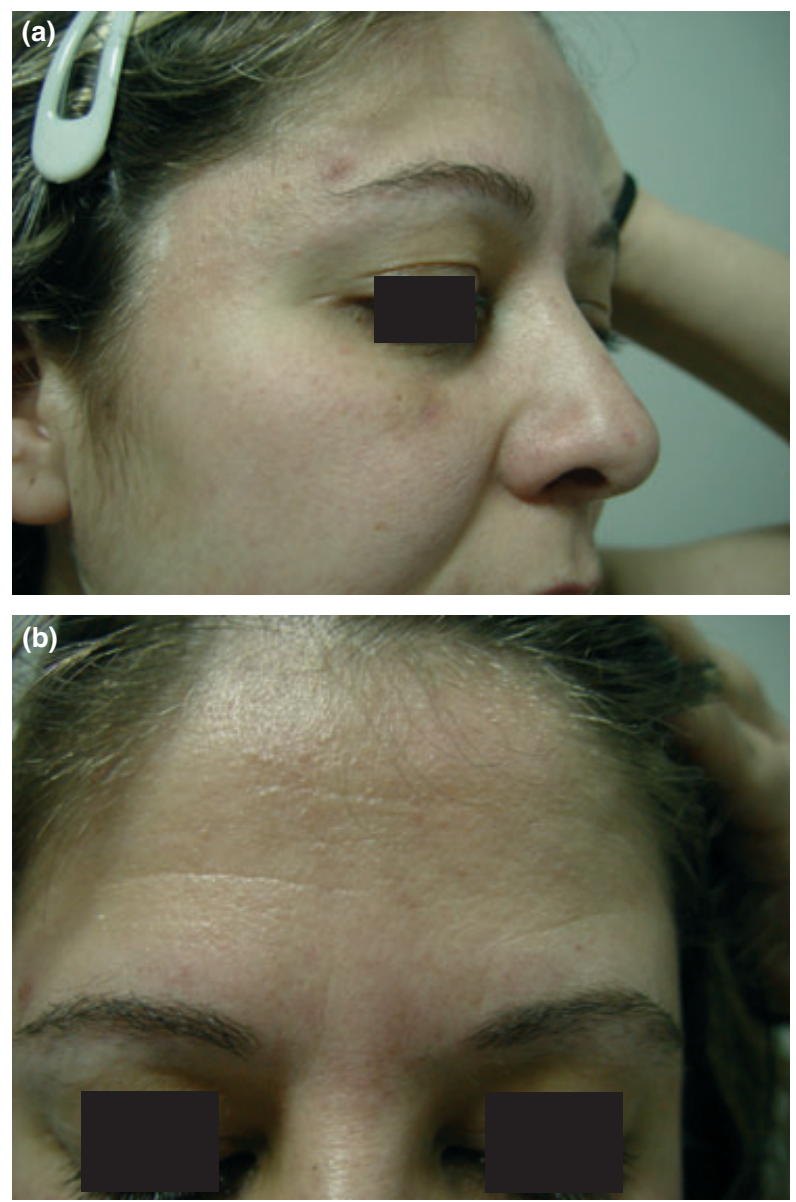

Figure 2 (a) and (b) After treatment with rituximab

The successful use of rituximab in over 30 cases of resistant PV has been reported. ${ }^{6-8}$ In most cases, the response to rituximab was rapid, with improvement noted within the first 2-6 weeks, and it was well tolerated. However, four serious infections were reported, including pneumonia, a relapse of septic arthritis of the hip, sepsis, and fatal Pneumocystis carinii pneumonia. ${ }^{6}$ This case confirms and underlines the importance of rituximab in the treatment of recalcitrant PV.

Filipa Ventura, MD

Joana Rocha, MD

José Carlos Fernandes, MD

\section{Apocrine hidrocystoma on the penis of a 40 -year-old man}

A 40-year-old man was referred to our department for evaluation of an asymptomatic lesion over his penis for the last four years, which had increased in size over the
Department of Dermatology and Venereology

Hospital de Braga

Braga

Portugal

E-mail: filipamanuelventura@hotmail.com

Álvaro Machado, MD

Department of Neurology

Hospital de Braga

Braga

Portugal

Celeste Brito, MD

Department of Dermatology and Venereology

Hospital de Braga

Braga

Portugal

\section{References}

I Engineer L, Bhol KC, Ahmed AR. Analysis of current data on the use of intravenous immunoglobulins in management of pemphigus vulgaris. J Am Acad Dermatol 2000; 43: I049-I057.

2 Katz U, Achiron A, Sherer Y, et al. Safety of intravenous immunoglobulin (IGIV) therapy. Autoimmun Rev 2007; 6: 257-259.

3 Wright SE, Shaikh ZHA, Castillo-Lugo JA, et al. Aseptic meningitis and abducens nerve palsy as a serious side effect of high dose intravenous immunoglobulin used in a patient with renal transplantation. Transpl Infect Dis 2008; IO: 294-297.

4 Looney RJ, Anolik JH, Campbell D, et al. B cell depletion as a novel treatment for systemic lupus erithematosus. Arthritis Rheum 2004; 50: 2580-2589.

5 Edwards JC, Szczepanski L, Szechinski J, et al. Efficacy of B-cell targeted therapy with rituximab in patients with rheumatoid arthritis. N Engl J Med 2004; 350: 2572258 I.

6 Carr DR, Hefferman MP. Off-label uses of rituximab in dermatology. Dermatol Ther 2007; 20: 277-287.

7 Jessop S, Khumalo NP. Pemphigus: a treatment updated. Am J Clin Dermatol 2008; 9: I47-I 54.

8 Faurschou A, Gniadecki R. Two courses of rituximab (anti-CD20 monoclonal antibody) for recalcitrant pemphigus vulgaris. Int J Dermatol 2008; 47: 292-294.

last months. His past medical history was irrelevant. He referred no symptoms, and he denied traumatism and risky or vigorous sexual activities.

Physical examination revealed a painless, well-defined, serpinginous mass measuring $3 \times 0.5 \mathrm{~cm}$ over his right 